\title{
Visitors and Residents: mapping student attitudes to academic use of social networks
}

\author{
Fiona Wright ${ }^{a}$, David White ${ }^{b}$, Tony Hirst ${ }^{c}$, Alan Cann ${ }^{a^{*}}$
}

\footnotetext{
${ }^{\text {a }}$ School of Biological Sciences, University of Leicester, UK.

${ }^{\mathrm{b}}$ Technology-Assisted Lifelong Learning (TALL), Department for Continuing Education, University of Oxford, UK.

${ }^{\mathrm{C}}$ Department of Communication and Systems, The Open University, Milton Keynes, UK.
}

\footnotetext{
* Corresponding author. Department of Biology, Adrian Building, University of Leicester, University Road, Leicester LE1 7RH, UK. Email: alan.cann@le.ac.uk
}

\section{Published:}

Fiona Wright, David White, Tony Hirst \& Alan Cann (2013) Visitors and Residents: mapping student attitudes to academic use of social networks. Learning, Media and Technology, doi:

10.1080/17439884.2013.777077 http://dx.doi.org/10.1080/17439884.2013.777077

\begin{abstract}
The visitors and residents model of Internet use suggests a continuum of modes of engagement with the online world, ranging from tool use to social spaces. In this paper we examine evidence derived from a large cohort of students to assess whether this idea can be validated by experimental evidence. We find statistically significant differences between individuals displaying "Visitor" or "Resident" attitudes, suggesting that the Visitors and Residents model is a useful typology for approaching and understanding online behaviour. From our limited sample we have been able to produce evidence that the Visitors and Residents labels are statistically robust. This demonstrates that the Visitors and Residents approach provides a valuable framework for those considering the use of social tools in educational contexts.
\end{abstract}

Keywords: data visualization, higher education, peer education, social networks. 


\section{Introduction}

It is difficult to overestimate the impact that social networks have had on student life. The situation is complex, with positive impacts on social integration (Madge et al 2009), and an intricate relationship between Facebook use, student engagement and academic achievement (Junco $2012 \mathrm{a}, \mathrm{b}$ ). Used appropriately, social software can develop the collaboration and communication skills valued by employers and offer a less instructor-centred approach at a time when instructor-centred learning may be losing effectiveness (Brown 2008; Hamilton and Singwhat, 2010) due to many factors, including overcrowded curricula, declining staff-student ratios and intense exposure to peer-driven social media. Analysis of online social networks has revealed that students form social networks consisting mainly of those with similar academic performance (Dawson 2010; Lewis et al 2012). As Web-based services have pervaded academic life from the social sphere (Alexander 2008), it is commensurate on educators to ensure that graduates are digitally literate, alongside the accepted skills of traditional communication and numeracy.

To make sense of online student behaviour, we need adequate frameworks which describe online interactions. Use of Web 2.0 in academic contexts represents the general movement of the Internet away from static, read-only formats towards a dynamic user-based experience where users generate the content on social platforms (Cormode and Krishnamurthy 2008). The "participatory Web" idea implies that the majority of Internet users behave in a Resident-like fashion, using sites as social spaces for sharing and discussion, whereas in reality, Internet user behaviour seems to be best described by the Pareto Principle, or "One Percent Rule", also known as "participation inequality". This "law of the vital few" states that, for many events, roughly $80 \%$ of the effects come from $20 \%$ of the causes (Ryan 2010).

Patterns of Internet use can be described by the Visitors and Residents paradigm (White and LeCornu, 2011). In this model, "Visitors" use the Internet in functional terms as a tool. In contrast, "Residents" see the Internet as a social space. The distinction between the two categories is relative rather than absolute - the Visitors and Residents model recognises the likelihood that Internet users form a continuum between these two extremes. While making no qualitative judgement of the superiority of one approach over the other, a prediction of both the Visitors and Residents model and the Pareto Principle would be that Visitors predominate over a small number of "noisy" Residents online, and it has been argued that the efficiency of the instrumental Visitor approach may have considerable benefits (White 2011).

While the Visitors and Residents idea has been much discussed, little evidence has been presented to attempt to validate or invalidate the concept behind the model. We still have relatively little understanding of what motivates individuals to use particular approaches or strategies when engaging with an information environment. This lack of understanding makes the task of facilitating 'digital literacy' skills challenging as literacy has to be defined against the motivations and goals of those individuals being taught. Individuals' shifting engagement with the information environment appears to have radically changed in the last decade, yet it is unclear whether this is the effect of larger cultural changes brought about by the web or of new attitudes towards education as a whole (Connaway et al 2011).

In order to progress the discussion, we have examined a large student cohort, developing techniques for mapping Visitor and Resident attributes, in order to determine if these terms are genuinely useful in describing and thinking about online behaviour. Here we present evidence that 
there are statistically significant differences between individuals displaying Visitor or Resident attitudes, suggesting that the model is valid and can be used effectively to describe observed behaviour online.

\section{Background}

All first year undergraduate students in the School of Biological Sciences at the University of Leicester (approximately 250 students per year) undertake a key skills module that encompasses I.T. and numeracy skills (Cann and Badge, 2011). This module is designed to support subjectspecific learning on all other modules. Previously we have shown that academic-related student contributions to a public social network as part of this module can be seen as a proxy for student engagement (Badge et al 2012).

In 2011 we moved our student network to the newly available Google+ platform (plus.google.com). Google+ is an online social network with fine-grained privacy controls based on the idea of sharing content with defined user "Circles" (see: bit.ly/ysD563), but more importantly, it is distinct and separate from Facebook (facebook.com), and so avoids "context collapse" (Marwick and boyd 2010) arising from the overlap of social and professional online identities (Baran 2010). Guidance and assessments are delivered to students on these modules via an institutional virtual learning environment (VLE, Blackboard), supplemented with twice weekly face to face help sessions. Students were informed that contributions to Google+ over the course of the term would contribute $25 \%$ of the overall module mark, including discussion of degreerelevant items shared and discussed from Google Reader RSS feeds, another taught component of the module, and other Internet sources. Students required minimal support in using the Google+ network but online feedback was given and face to face support was available if requested.

\section{Methodology}

The study described in this paper was approved by the University of Leicester Committee for Research Ethics Concerning Human Subjects. In order to examine the full range of content, interactions and motivation generated by this cohort of Google+ users, we have developed a three-pronged approach to social network analysis based on that suggested by De Laat et al (2006) consisting of:

1. Context analysis of metadata focusing on the experiences of the participants to find out 'why they are talking as they do'.

2. Network analysis to find out 'who is talking to whom'.

3. Content analysis to find out 'what users are talking about'.

This approach has previously been used successfully for analysis of student behaviour online (Badge et al 2012). Context was derived from an online questionnaire designed to elucidate characteristics of Visitors and Residents based on the original description of the model (White and LeCornu 2011) and subsequent analysis (Connaway 2011). Questionnaire design followed the best practices described by Krosnick and Presser (2010). The questionnaire was administered anonymously to all students on the module but allowed respondents to identify themselves if they wished to do so. The restrictions imposed by the ethical approval granted for this study allowed us no alternative but to take this approach, limiting the number of respondents who could be 
identified for subsequent network analysis. Network analysis was performed as follows. Google+ supports an asymmetric friend/follower model, i.e. A can follow B without B following A. User data was extracted from OpenSocial application programing interface (API) (http://docs.opensocial.org) and converted to graph.ml format using a python script (https://gist.github.com/1288134). Network visualization was carried out using Gephi (http://gephi.org), forceatlas2 layout, groupings coloured by modularity (Blondel et al 2008).

Data for content analysis was extracted directly from Google+ for selected users (see Results). Contextual meta analysis was performed via a specially designed questionnaire. Statistical analysis was performed using R 2.14.1 (R Development Core Team, 2011).

\section{Results}

\section{Context analysis}

Over the 10 week analysis period, the 257 students in the study generated a huge volume of data in the form of contributions to Google+, consisting of thousands of posts and hundreds of thousands of words. Summary analysis showed that many students fell into common patterns of activity, posting an average of 2-3 items per week, and with a network size of approximately 200. Rather than attempting to analyse much repetitive and thus uninformative data, representative examples were selected for detailed analysis. The starting point for the analysis of online behaviour was a specially designed questionnaire administered via the VLE (Table 1). In addition to asking general questions about the module, this also contained questions specifically designed to elucidate characteristic Visitor or Resident attitudes. 109/257 students completed the questionnaire ( $42 \%$ response rate). Responses to four questions were used to map respondents onto a horizontal Visitor-Resident axis (figure 1):

Q8) How often did you visit Google+ without intending to make an assessed contribution? Residents are more likely to visit for interaction rather than just to earn marks (Likert scale). Q9) How far do you agree with the statement I am comfortable discussing what I am learning with others? - Residents are more likely to agree with this statement (Likert scale).

Q11) When I have researched the information for a topic, I then organise my thoughts: (click all that apply)

- $\quad$ By publicly discussing my understanding on a social network or blog

- $\quad$ By writing about what I have found without expecting others to contribute

- $\quad$ A mixture of public and private writing

- $\quad$ Privately on a computer (offline)

- $\quad$ Offline, (e.g. pen and paper)

- Responses ranging from Resident to Visitor-like in nature.

Q12) How trustworthy did you think the information and resources posted on Google+ were? Residents are more likely to find shared information trustworthy (Likert scale).

Responses to the following question were used to map respondents onto a vertical InstitutionalPersonal axis (figure 1):

Q14) Do you feel Google+ is part of this module or your personal space where you can interact with others? - Residents are more likely to view Google+ as a personal space (Likert scale). 


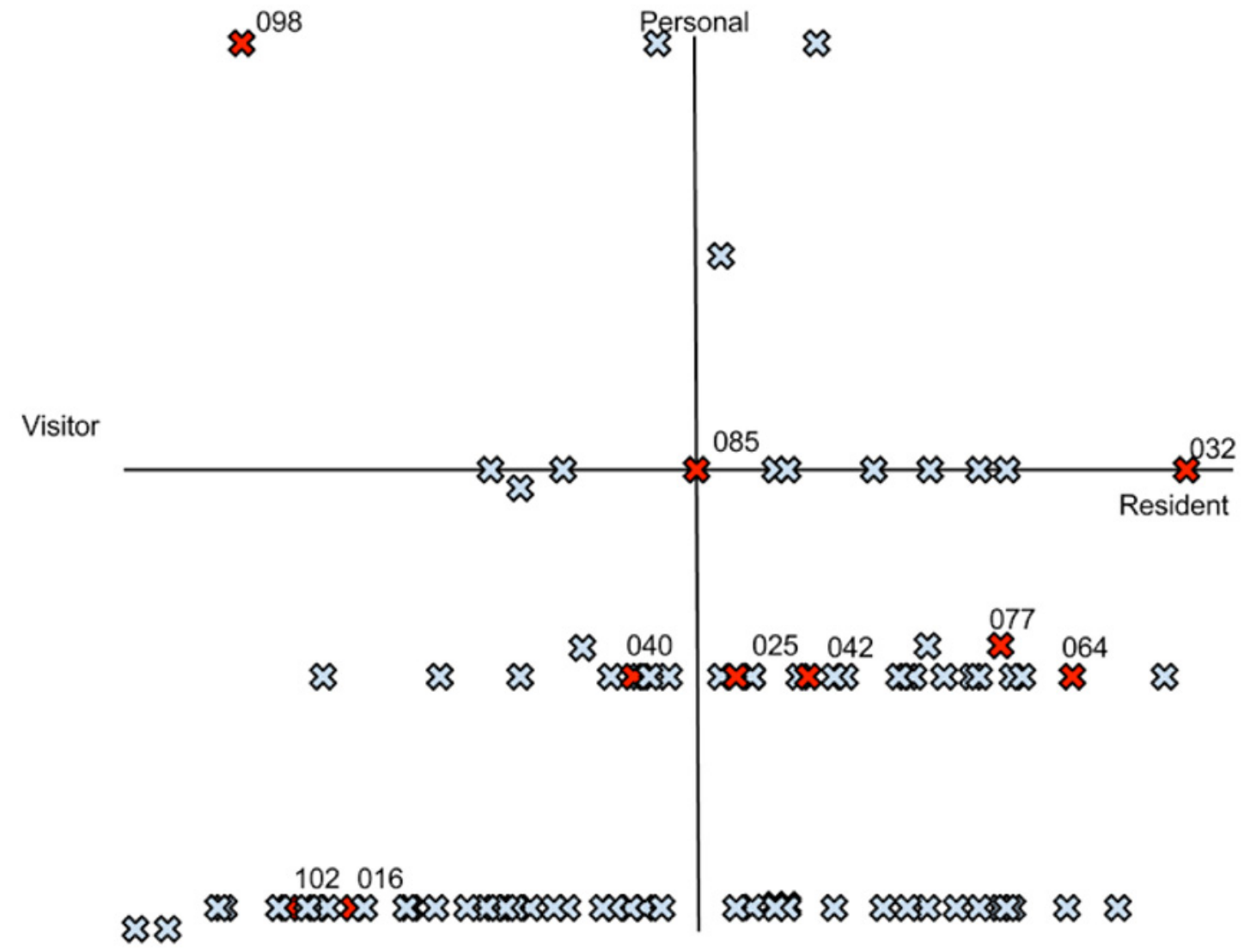

Institutional

\section{Figure 1: Mapping student use of Google+}

Responses to four questions $(8,9,11,12$, see table 1$)$ were used to map respondents onto a horizontal Visitor-Resident axis, and an additional question (14, see table 1 ) onto a vertical Institutional-Personal axis. The students indicated by red symbols were selected as representative of the cohort for further analysis.

In response to the question How easy to use was Google+? only $4 \%$ of students responded Difficult or Very Difficult, confirming discussions during the module indicating that the cohort felt at ease with the tool. Student attitudes to privacy on Google+ varied but were generally favourable. Many questionnaire responses mentioned the ease with which Circles could be used to control levels of privacy. Almost without exception during the module, all student posts were shared in a limited fashion to defined Circles rather than shared publicly. (In a subsequent module, a small number of students from this cohort started to share some items publicly, but limited sharing via Circles remained the dominant model.)

"I think that the privacy on Google+ is really great actually. Especially the fact that you can limit your posts to specific groups. Really helpful."

"Google+ is very open and public but you can control to whom you share your posts with. I found this feature to be very helpful as I didn't want to clog up my family's stream with posts related to this module." 
A few students were opposed to the idea of being present on Google+. These responses often showed lack of understanding about privacy controls. In spite of advice to use an image as avatar rather than a photograph, one student commented:

"I resent the fact that typing my name into Google now bring up a picture of my face. As someone without any sort of social networking profile online, I will certainly close down my account at the first available opportunity."

The majority of students generally had more relaxed opinions of privacy on Google+:

"I don't mind the fact that my profile can be found through search engines. Each person had the opportunity to tailor their profile to their preferences (profile picture, location, etc.) also it was a good way for students to communicate privately e.g. regarding group work."

This was even true of students who mapped to the Visitor side of figure 1:

"Now that Google has allowed users to set their own options for privacy, I feel a lot safer and more confident that my usage and web footprints aren't accessible to others. I use Google SSL when I can, and use quite a few Greasemonkey scripts to kill web-crawlers and user data all across Google websites."

"I have no problems with privacy on Google, since any information I provided was purely for use during my course, and not personal."

Although set in an assessment context as an academic rather than a social space, $38 \%$ of questionnaire respondents indicated that they visited Google+ without intending to make an assessed contribution at least once a day, and $73 \%$ at least once a week. Only $11 \%$ of respondents indicated they disagreed with the statement "I am comfortable discussing what I am learning with others".

Two questions on the questionnaire were not used for the Visitor-Resident mapping exercise and could thus be used to compare the Visitor and Resident subgroups (i.e. excluding any students who mapped on the midline of figure 1):

Q7) How easy to use was Google+?

Comparing the responses of the two groups to this question, there was no statistically significant difference between Visitor and Resident scores (Fisher's exact test, $p=0.09198$ ).

Q15) How far do you agree with the statement: I found Google+ useful for my degree?

In contrast to Q7, there was a highly significant difference between Visitor and Resident scores for this question (Fisher's exact test, $p=0.001175$ ). This difference between Visitors and Residents is thus not attributable to technical difficulty (Q7), with Residents finding Google+ more useful than Visitors.

\section{Network analysis}

From the map (figure 1), 10 questionnaire respondents (016, 025, 032, 040, 042, 064, 077, 085, 098 and 102) were selected for detailed analysis. The criteria for selection were as follows: 
1. Representative of the population based on positioning on the Visitor-Resident map (figure 1).

2. Full set of questionnaire responses available. Under the terms of the ethical approval for this study, students were given a choice of whether to identify themselves by name in the questionnaire return or remain anonymous. Only self-named students $(18 / 109)$ could be identified for network mapping via the Google+ API.

Unfortunately, the limitations of the dataset available meant that no suitable respondents mapping in the extreme of the Resident-Institutional quadrant were available, although students 064 and 077 represent this segment reasonably well. No students mapped in the extreme range of the Resident-Personal quadrant, presumably reflecting the fact that the use of Google+ was mandated and assessed as part of a taught module. Student 098 was selected as an extreme representative of the Visitor-Personal quadrant, although due to privacy settings used by this student it was not possible to extract data from the Google+ API for this student (see Discussion). Network diagrams for the selected students were drawn as described in the Methodology section (figure 2):
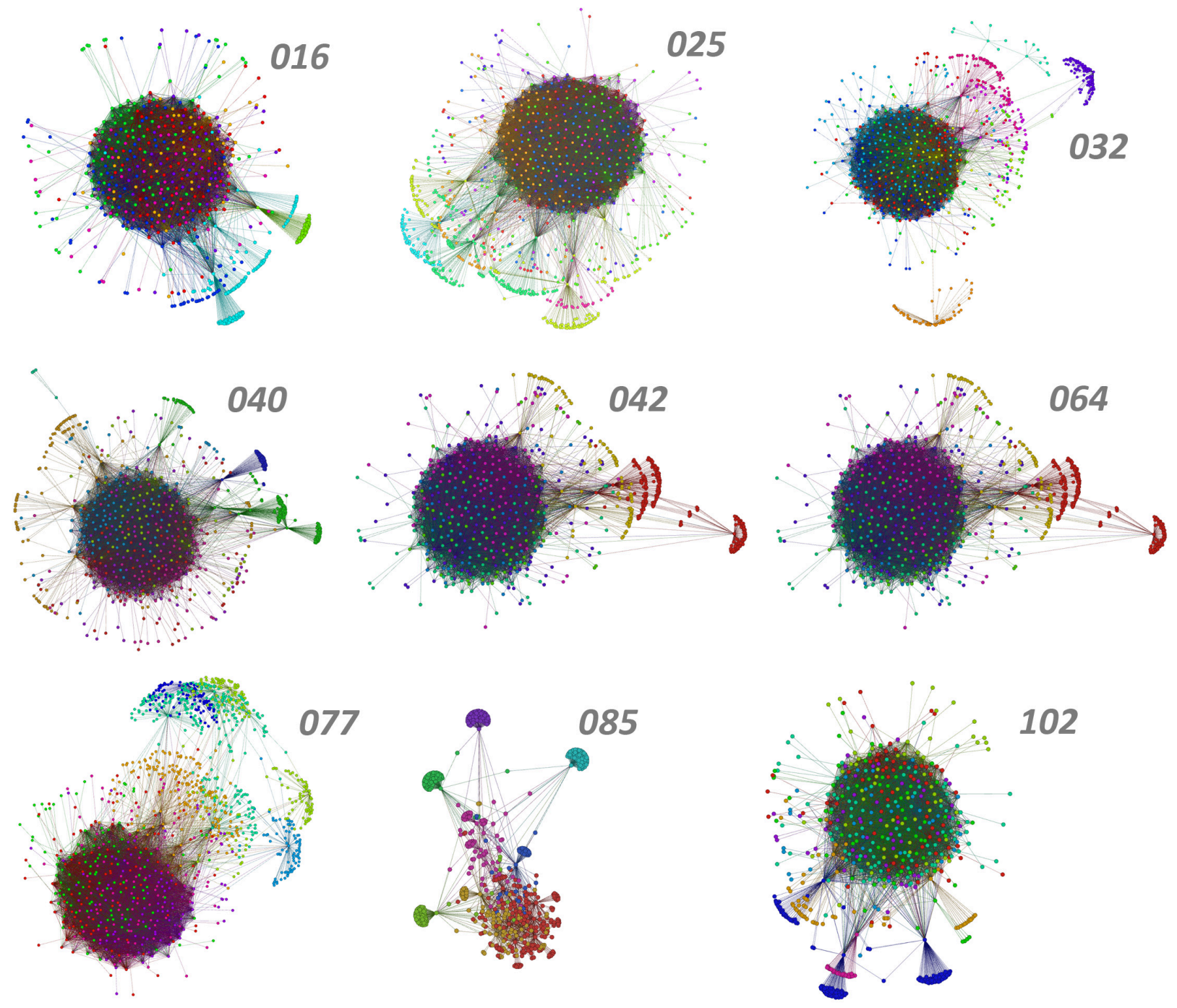

102

Figure 2: Network visualization diagrams

Network visualization diagrams for selected students (red symbols in figure 1), drawn as described in the Methodology section. 
The network diagrams shown in figure 2 depict friendship networks of the people followed by a specified account (which may or may not include people who are followed by the specified account). In a sense, they represent the community or communities of practice an individual has access to via their friendship network, either directly through following an individual directly, or at one step remove (that is, via one or more of their friends) (Wenger 1999). In these diagrams, nodes (dots) represent students and edges (connecting lines) are "friend" connections between them, meaning at least one of the pair connected by the line is "following" the other via a Google+ Circle and will see content shared with them via the network. Most of these network diagrams are similar in size and shape. This is a result of how students were recruited via Circle sharing, forming the dense module cluster in the centre of most of the diagrams. This can be viewed as a positive outcome, ensuring good communication (high connectedness) between students on the module. The outgroups flanking the central cluster in these diagrams arise from Google+ accounts participants have chosen to follow other than other students on the module. Academic staff supporting the module tend to map fairly close to the cluster, more distant outgroups represent other people on Google+ students have chosen to follow, including scientists and journalists sharing interesting content, and in a few cases, celebrities recommended by Google+. However, the predominant network pattern is students choosing to focus mostly on a tight module cluster with little evidence of "non-academic" distractions. There is no indication from the network diagrams in which quadrant of the Visitor-Resident map (figure 1) students are located. In addition, there was no significant correlation between network size and map position on the Visitor-Resident or Institutional-Personal axes. A notable exception to this general trend is student 085 , who maps in the very centre of the chart based on their questionnaire responses. This student also has a much smaller network $(n=23)$ than the typical size $(\sim n=200)$ for the cohort (see Discussion).

\section{Content analysis}

Content analysis for the 10 representative students selected from figure 1 was performed by direct extraction of all the posts made by the students during the module. The majority of posts (75\%) were in the form of course-related object-centred discussion threads derived mostly from Google+ RSS feeds (including scientific journal feeds), YouTube (a popular content source) and other online content. A further $18 \%$ of posts involved discussion and/or reflection on current academic activity. $7 \%$ of posts contained or consisted of questions or other students and for staff, largely administrative in nature, bit some clarifying content from lectures, practical classes, etc. All of the posters had a larger proportion of academically relevant articles than of anything else in their posts with very few non-degree related items posted. Word frequency analysis (not shown) reflects this concentration on academic (module-specific) rather than social or administrative (e.g. asking organisational questions) use, with object-centred discussion threads originating from scientific articles predominating. This confirms the data in figure 1 that most students used Google+ in this context for institutional rather than personal reasons.

Figure 3 shows a graph of the number of words posted by students arranged by map position of the Visitor-resident axis of figure 1. Although there is a general trend for residents to post more content, there is considerable variation between individuals in this sample and the correlation between Visitor-Resident positioning and word count is not statistically significant for this sample. 


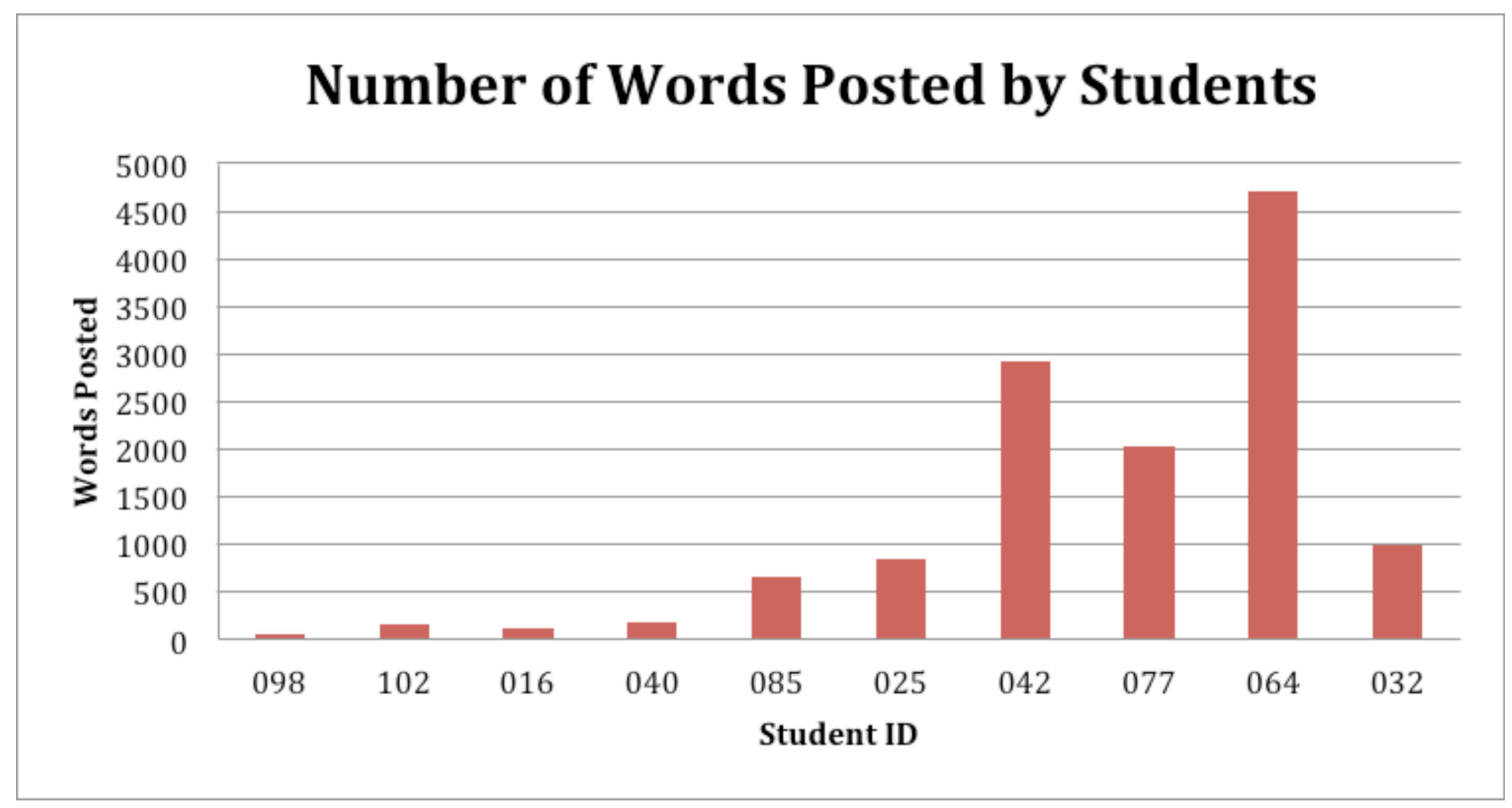

Figure 3: Number of words posted by students on Google+

A graph showing the number of words posted by each member of the selected cohort to Google+. Students are arranged from left to right in order of Visitor-Resident score as on figure 1. Generally, students with stronger Resident tendencies post more words, but there is considerable variation between individuals.

\section{Discussion}

The Visitors and Residents model was originally proposed in response to "Digital Natives" concept suggested by Marc Prensky (Prensky 2001). Among other criticisms of Prensky's idea is the lack of evidence supporting it. We set out to investigate whether student use of the Google+ social network could usefully be interpreted in terms of this newer model. To do this, we have applied a three-fold approach which examines context-motivation, network structure, and content posted. To establish context, questionnaire metadata is the key to interpretation of content extracted directly from Google+. Without this additional window into user attitudes content alone is difficult to interpret in a meaningful way. Only by putting the three threads of context-network-content together does a true picture of user motivation emerge. Content alone, although the easiest data to extract and analyse, is particularly superficial in terms of assessing participation and engagement. The Visitors and Residents model is particularly useful in the context of this approach as it is based around genres of participation (Ito 2009) which focus on attitudes and motivations rather than skills. In this way it explores the 'why' not the 'what' of technology usage. The notion of genres of participation was first used in the context of digital youth culture; however, it effectively translates across to the academic context because engaging in study via technology can be understood as one aspect of a broader digital culture.

Using the results of the questionnaire, respondents who chose to identify themselves were mapped in terms of answers indicative of Visitor or Resident tendencies, and of institutional (i.e. course-related) or personal use of the service (figure 1). While this could potentially introduce bias in terms of sampling, the terms of the ethical permission for this study ruled out the possibility of 
forcing questionnaire respondents to identify themselves. A counter argument is that knowing they were identifiable could have made questionnaire responses inherently less reliable.

Network size does not correlate with position on either the Visitor-Resident or Institution-Personal axes. Indeed, because of deliberate Google+ Circle sharing to engender a strong cohort effect for pedagogic reasons, most of the network diagrams look strikingly similar, with a central hairball representing the module cohort and peripheral outgroups consisting of academic staff, a limited number of friends or acquaintances and unconnected Google+ users such as media types and recommended celebrities. There is some indication that students mapping in the resident sector (e.g. students 032, 064, 077, figure 2) have somewhat more diffuse networks with more outgroups than the tightly clustered Visitor networks (e.g. students 016, 040, 102, figure 2), but this observation cannot be supported definitively by network statistics such as diameter, density, modularity, or path length generated by Gephi.

Two students stand out in this mapping exercise. Data from student 098, who maps in the extreme Visitor-Personal quadrant of figure 1, was not available for network analysis due to the privacy settings chosen by this individual. However, although anecdotal, it is noteworthy that this student was struggling academically and subsequently dropped out of the course. There is a possible indication here of network activity as a proxy for academic engagement and an early warning sign (see Badge et al 2012). Student 085 has a very small network (figure 2), heavily biased towards academic staff rather than student peers. This student is known to be a non-E.U. student whose first language is not English, and to display attitudes favouring academic authority rather than peer learning. Although the questionnaire responses from this student map them in the very centre of the diagram in figure 1 , there is a possibility that this is an aberrant map position based on unreliable questionnaire answers. Can we conclude that adaptable students engage well in any context and get the best out of it, employing a strategy which might be described as progressive fluency or agility. Such students do not see their mode of engagement as a fixed set of skills but as constantly evolving in the Digital Literacies style. In contrast, students with fixed academic attitudes may struggle in the fluid environment of networked peer learning.

Overall, students were generally positive about the use of Google+ in this academic context, most finding it easy to use, and in particular making favourable comparisons with Facebook in terms of privacy:

"I think Google has more privacy because unlike facebook, you are only posting things relevant to your modules not personal things which you could but we did not in Google+."

"It seems pretty private as my friends only use facebook whilst I only used Google Plus for this module."

"People are addicted to facebook because they can post whatever they want. Not exactly the same in Google+ but it would be nice if someone can post something not relevant to their course yet, you could learn new things from it and still get marks."

"Although during this term I used Google+ primarily for this module I do intend to use it for my role as an Academic Officer (Student Union Parliament) and Course Rep. I intend to share my knowledge about new events and activities taking place at the university and maybe even information that is covered during the meetings."

"At first I found the aspect and idea of Google+ pointless and an annoyance but following the essays, and the information shared I have actually learned to really enjoy it and look forward to finding new elements to post." 
"I don't see why G+ should be assessed. It is a good idea to encourage people to share information and to help each other, but you shouldn't feel obligated to write long-winded paragraphs alongside a video you've found just to get some credit. Sharing information isn't about getting credit, it's about helping your peers."

Driving student behaviours by linking social tools to assessment continues to be problematic. On the one hand, in most contexts, very few students will engage with a social tool unless they are "forced" to so do by a reasonable academic tariff (Wilkinson 2011; Junco et al 2012; unpublished data), eliminating the possibility of forming peer learning cohorts. Students in this situation may be "acting-as" Resident rather than "being" Resident. Promoting peer learning and support has to be an important motivation in the adoption of social tools in academic contexts. In our experience, $15-30 \%$ of module marks is sufficient to motivate students without unduly downplaying the significance of academic content in the rest of the course. On the other hand, by pulling the assessment lever and forcing a tool into a particular academic context, only a minority of students continue to use the tool after the end of the module - around $10 \%$ in the case of the cohort discussed here - although this figure underestimates the number of "lurkers" who continue to read but not to post themselves (Cann and Badge 2011). The majority of academics employ "conservative approaches to conducting assessment and their novice approaches to utilising social web technologies are factors which seriously limit realising the potential of Web 2.0 for medium or high-stakes assessment" (Gray et al 2012).

When academics are primarily Visitors, it is not surprising that students also display these learned behaviours in academic contexts, in contrast to their peer orientation in non-academic networks such as Facebook. Traditional models of academia built around lone scholars acting in isolation still predominate in our thinking about and assessment of learning. Incorporating social tools into education may not provide sufficient drivers to change this. A Resident attitude of dialogue and collaboration may need to precede any social revolution in education rather than relying on a technodeterminist toolbox provided by Google or any other external agent.

\section{Conclusions}

We have shown that the Visitors and Residents model can be used to map student attitudes to academic us the Google+ social network. This apparently homogenous group of students - similar ages, educational achievements, subject specialism - displays a diverse range of modes of engagement to academic content, to self-representation and with their peers. The Residents and Visitors model reflects the true situation much better than the Digital Natives concept which spawned it. Academic courses must be carefully structured to adequately encompass this diversity.

Are the findings presented here generalizable to other social tools or online spaces? We would encourage others to utilize the framework described here to investigate student attitudes and behaviours when online tools are adopted. Although the Visitor and Resident labels only represent the extremes of a continuum of behaviour, this study has produced statistical evidence that Residents report online tools such as Google+ to be more useful academically than Visitors do. It is not clear where the academic benefits of these behaviour patterns lie, but it must surely be worthy of further consideration in terms of using such tools in education. The next move must be to translate this research into a more accessible form for the benefit of those engaged in the practice of teaching online. 


\section{References}

Alexander, B. 2008. Social Networking in Higher Education, In Katz, R.N., The Tower and the Cloud: Higher Education in the Age of Cloud Computing, Campanile, University of California, Berkely, EDUCAUSE, pp 197-201.

Baran, B. 2010. Facebook as a formal instructional environment. British Journal of Educational Technology. 41 (6): E146-E149

Badge, J.L., Saunders, N.F.W. and Cann, A.J. 2012. Beyond marks: new tools to visualise student engagement via social networks. Research in Learning Technology 20: 16283.

Blondel, V.D., Guillaume, J.L., Lambiotte, R. and Lefebvre, E. 2008. Fast unfolding of communities in large networks. Journal of Statistical Mechanics: Theory and Experiment 2008: P10008.

Brown, J.S. 2008. How to connect technology and content in the service of learning. Chronicle of Higher Education, 55, 8. available at: http://chronicle.com/free/v55/i08/08a12001.htm

Cann, A.J. and Badge, J. 2011. Reflective Social Portfolios for Feedback and Peer Mentoring. Leicester Research Archive. http://hdl.handle.net/2381/9704

Connaway, L.S., White, D. and Donna Lanclos. 2011. Visitors and residents: What motivates engagement with the digital information environment? Proceedings of the American Society for Information Science and Technology 48(1): 1-7.

Cormode, G. and Krishnamurthy, B. 2008. Key differences between Web 1.0 and Web 2.0. First Monday 13, 6. available at: www.uic.edu/htbin/cgiwrap/bin/ojs/index.php/fm/article/view/2125/1972

Dawson, S. 2010. Seeing the learning community: An exploration of the development of a resource for monitoring online student networking. British Journal of Educational Technology, 41, 736752.

De Laat, M., Lally, V., Lipponen, L. and Simons, R.J. 2006. Analysing student engagement with learning and tutoring activities in networked learning communities: a multi-method approach. Int. J. Web Based Communities, 2(4): 394-412.

Gray, K., Waycott, J., Clerehan, R., Hamilton, M., Richardson, J., Shearde, J. and Thompson, C. 2012. Worth it? Findings from a study of how academics assess students' Web 2.0 activities. Research in Learning Technology 20: 16153 http://www.researchinlearningtechnology.net/index.php/rlt/article/view/16153

Hamilton, J., and Singwhat, T. 2010. Smart utilization of tertiary instructional modes. Computers and Education 54(4): 1036-1053.

Ito, M. 2009. Hanging out, messing around, and geeking out: kids living and learning with new media. Cambridge, Mass, MIT Press. ISBN 0262013363.

Junco, R. 2012a. Too much face and not enough books: The relationship between multiple indices of Facebook use and academic performance. Computers in Human Behavior, 28(1): 187-198.

Junco, R. 2012b. The relationship between frequency of Facebook use, participation in Facebook activities, and student engagement. Computers and Education, 58(1): 162-171.

Junco, R., Elavsky, M.C. and Heiberger, G. 2012. Putting twitter to the test: Assessing outcomes for student collaboration, engagement and success. British Journal of Educational Technology 01 March 2012. doi: 10.1111/j.1467-8535.2012.01284.x http://onlinelibrary.wiley.com/doi/10.1111/j.1467-8535.2012.01284.x/abstract

Krosnick, J.A., and Presser, S. 2010. Question and questionnaire design. Handbook of Survey Research. 2nd edition. Bingley, UK: Emerald: 263-314.

Lewis, K., Gonzalez, M. and Kaufman, J. 2012. Social selection and peer influence in an online social network. Proceedings of the National Academy of Sciences 109(1): 68-72. 
Madge, C., Meek, J., Wellens, J. and Hooley, T. 2009. Facebook, social integration and informal learning at university: It is more for socialising and talking to friends about work than for actually doing work. Learning, Media and Technology, 34(2): 141-155.

Marwick AE and boyd d 2010. I tweet honestly, I tweet passionately: Twitter users, context collapse, and the imagined audience. New Media and Society. doi: 10.1177/1461444810365313. http://nms.sagepub.com/content/13/1/114

Prensky, M. 2001. Digital Natives, Digital Immigrants: Do They Really Think Differently? On the Horizon, 9, 1-6.

$\mathrm{R}$ Development Core Team 2011. $R$ : A language and environment for statistical computing. $\mathrm{R}$ Foundation for Statistical Computing, Vienna, Austria. ISBN 3-900051-07-0, http://www.Rproject.org

Ryan, J. 2010. A History of the Internet and the Digital Future. London: Reaktion Books.

Wenger, E. 1999. Communities of practice: Learning, meaning, and identity. Cambridge University Press.

White, D.S. 2011. The cost of Residency? [online] Available at: http://tallblog.conted.ox.ac.uk/index.php/2011/08/15/the-cost-of-residency/

White, D.S. and Le Cornu, A. 2011. Visitors and Residents: A New Typology for Online Engagement. First Monday: 16, http://firstmonday.org/htbin/cgiwrap/bin/ojs/index.php/fm/article/viewArticle/3171

Wilkinson, T. 2011. Pass/fail grading: not everything that counts can be counted. Medical Education 45(9) 860-862. 
Table 1: Student questionnaire

An online questionnaire was administered to all students on the module. The response rate was $42 \%(109 / 257)$. A summary of responses relevant to figure 1 is shown.

\section{Q 1. Name (optional):}

$17 \%$ of respondents chose to identify themselves.

Q 8. How often did you visit Google+ without intending to make an assessed contribution?

At least once a day

$38 \%$

At least once a week

$35 \%$

Occasionally (every other week)

$16 \%$

Rarely (at least once during the term)

$5 \%$

Never

$7 \%$

Q 9. How far do you agree with the statement "I am comfortable discussing what I am learning with others"?

Strongly agree $\quad 25 \%$

Agree $\quad 43 \%$

Neutral $22 \%$

Disagree $\quad 6 \%$

Strongly disagree $\quad 5 \%$

Q 11. When I have researched the information for a topic, I then organize my thoughts: (click all that apply)

By publicly discussing my understanding on a social network or blog $\quad 10 \%$

By writing about what I have found without expecting others to contribute $\quad 19 \%$

A mixture of public and private writing $\quad 29 \%$

Privately on a computer (offline) $\quad 38 \%$

Offline, (e.g. pen and paper) $\quad 61 \%$

Q 12. How trustworthy did you think the information and resources posted on Google+ were?

$\begin{array}{ll}\text { Very reliable } & 3 \% \\ \text { Mostly reliable } & 76 \% \\ \text { Unsure } & 19 \% \\ \text { Unreliable } & 0 \% \\ \text { Very unreliable } & 1 \%\end{array}$

Q 14. Do you feel Google+ is part of this module or your personal space where you can interact with others?

Only used for this module $\quad 49 \%$

More for BS1010 than for personal use $\quad 35 \%$

A mixture of BS1010 and personal use $\quad 11 \%$

More for personal use than for this module $\quad 1 \%$

Mostly for my own use $\quad 3 \%$ 